\title{
EXPLORING THE GENDER STEREOTYPE THREAT THAT WOMEN EXPERIENCE IN TEAM-BASED EDUCATIONAL SETTINGS
}

\author{
Bryan HOWELL, Judith WESTWOOD, Becky FULLER, Asa JACKSON, Rebekah \\ RAWLINGS and Michaela HILL
}

Brigham Young University

\begin{abstract}
Solitary women students participating in male majority design and development teams often experience inadvertent stereotype threat. This paper explores the educational experience of undergraduate women participating in both majority male and majority female teams and how stereotype threat influences their educational experience. A 23-question survey distributed to thirty-eight female undergraduate students explores their experiences in both majority male and female group work. The results indicate women have an increased learning experience when participating in female majority teams. They experience increased decision-making and management responsibilities, experience more effective communication and influence, and feel ownership of projects and technical tasks. Participation on a majority female team amplifies positive emotional attributes and self-perception and increases courage, confidence, subject knowledge, and disciplinary cultural fit. To improve the learning experiences for all students, Design and Engineering educators should understand how to identify stereotype behaviour. This paper provides stereotype questions and topics to talk about with students and promotes a 60/40 gender composition when educators form project teams, thus improving students overall learning experiences.
\end{abstract}

Keywords: Women design teams, industrial design projects, project team creation, stereotype threat in education

\section{INTRODUCTION}

As an industrial design educator of 15 years, I have observed that women designers behave differently in majority female project teams than when they are the lone designer on a majority male team. I notice they are happier, highly engaged, produce better outcomes, and positively influence classroom dynamics. Many of these students also reported in their graduating exit interviews that their majority women team projects were "one of the most positive experiences" they had during their design education, indicating they experienced an increase in disciplinary growth and self-confidence and a decrease in the pressures and stresses associated with disciplinary learning.

In discussing this observation with the students, some explained that when they are in the minority on a majority male project team, they feel self-conscious, fearful and pressured to emulate or meet what they believe to be the expectations of their male peers' thoughts and actions. As a result, they also conceal their intrinsic values and thought processes to meet these perceived expectations. This behaviour is unfortunate and reflects a form of stereotype threat.

Steele (2011) discusses the role stereotypes play in day-to-day life and explains that 'stereotype threat' occurs when a person experiences a threatening situation where a negative stereotype of one of their identities exists [1]. Being in such a context elicits psychological arousal as the individual is wary of doing anything that may confirm the negative stereotype. Steele's other research collaborations indicate the effects of being in an environment where few women faculty or students, or where the curriculum marginalizes the experiences of women students, are enough to trigger a stereotype threat that undermines performance in math, science, and engineering fields [2].

While there is academic work addressing gender disparities facing women, the issue of stereotype threat deserves more attention within design and engineering education as it relates to group dynamics and specifically how educators form teams for group projects. 
Research focusing on the female experience in design education is limited, with only a few papers published within the last fifty years [3]. Woodcock et al. [4] determined that stereotype-like threat experienced over an extended time tends to lead to individuals leaving their field of study and eventually dissociating from that area of study or profession. The number of professional women designers in the design field is unknown in the US, while in the UK, it is $22 \%$ of the total design workforce [5]. For engineering, The Society of Women Engineers reports that women currently make up 13\% of the USA's professional workforce [6]. This gender disparity in the industry might reflect the stereotype threat experienced by women during their educational group experiences.

In recent years, governing bodies have begun to address these issues. For example, changes to standards for higher education institutions in the UK have emphasized equality, diversity, and inclusion (EDI) measures as requirements for receiving AHEP 4 accreditation [7]. Additionally, the USA and Japan have made legislative measures to ensure increasingly equal educational opportunities for all minorities, including the Strength and Diversity Act of the US and the MEXT initiative in Japan [8, 9]. While equality and diversity initiatives have emerged on the macro level, this study focuses on improving women's micro-interactions and learning experiences in design and engineering education courses.

To bridge the gap between legislation and the classroom, we first propose 23 stereotype focused questions educators could use to discuss or explore with all student's stereotype threat situations and experiences that could inadvertently be occurring in the classroom. Secondly, we propose eradicating the common practice of assigning the few women in a course equally across all project teams, which often isolates one woman on a majority male team.

\section{METHODS}

To explore the stereotype issues women in undergraduate design and engineering teams face in their educational experience, we interviewed three design students and one math student to gather insights on how their gender impacted their academic careers. Each interview was roughly an hour in duration, and the insights gathered formed much of the survey's framework and content.

A Qualtrics survey was administered to 58 undergraduate female students from Brigham Young University and Utah Valley University through a Facebook link. 54 respondents indicated enrolment in technology, engineering, or design. 57 of the respondents had participated in group projects in which they were in the minority as a woman, and 38 reported having experienced working in a predominantly female team for a group project in school.

We assessed data from the 38 respondents who reported experience with group projects under both majority male and majority female composition conditions for this study. Participation was voluntary; no students received compensation for participation.

The survey consisted of 23 'team participation' and 'self-perception' questions and 4 screening questions. Section 1 confirmed university enrolment, whether participants were studying in a technology, engineering or design field, and whether participants had experience participating in both male and female majority team projects. Section 2 evaluated the respondent's experiences to the 23 questions when participating on "male majority" teams, while Section 3 asked the same questions considering their experience on "female majority" teams.

\section{RESULTS}

The data was averaged for each survey question to expose potential trends and insights in participants' learning experiences. Participants ranked their experiences on a scale of 1-9, with 1 being 'strongly disagree' or the least favourable condition, and 9 being 'strongly agree' or the most favourable condition. For example, question 5 asks, "In groups with more men than women, I am included in decision making". The value ' 1 ' indicates participants' strongly disagree' they were included in decision making. In contrast, the value ' 9 ' indicates participants' strongly agree' they were included in decision making. A score of 5 represents neither a positive nor negative experience. Scores lower than 5 will be discussed as less favourable experiences, while scores above 5 will be addressed as more favourable experiences. In tables 1 and 2, the first column lists the 23 questions respondents were asked to rate. The second column lists average scores given by participants on a majority female team. The third column lists the average scores of participants on a majority male team. Finally, the fourth column indicates the difference in rating between the two gender majority conditions. 
Table 1: Team Participation scores between majority female and male teams. Notably all scores are higher in the majority female column

\begin{tabular}{|l|l|l|l|}
\hline & Majority Female & Majority Male & Difference \\
\hline We Fairly Distribute Technical Tasks & 7.21 & 5.10 & 2.11 \\
\hline I Have Opportunities for Leadership & 6.59 & 4.50 & 2.09 \\
\hline Communication is Easy & 7.05 & 5.05 & 2.00 \\
\hline We Share Project Ownership & 7.69 & 6.08 & 1.62 \\
\hline I am Engaged with My Team & 7.67 & 6.05 & 1.62 \\
\hline My Ideas are Considered & 5.72 & 4.13 & 1.59 \\
\hline My Peers are Persuaded by my Input & 5.26 & 3.75 & 1.51 \\
\hline I am Included in Decision-Making & 6.49 & 5.08 & 1.41 \\
\hline
\end{tabular}

Table 2: Self-Perception scores between majority female and male teams. Notably all scores are higher in the majority female column

\begin{tabular}{|l|l|l|l|}
\hline & Majority Female & Majority Male & Difference \\
\hline I Feel Confirmation that I Belong in this Major & 7.36 & 4.50 & 2.86 \\
\hline I am Willing to Show Weaknesses & 5.49 & 3.00 & 2.49 \\
\hline I Feel Included & 8.00 & 5.7 & 2.30 \\
\hline I Don't Change the Way I Talk & 6.77 & 4.55 & 2.22 \\
\hline I Feel Self-Assured & 6.26 & 4.23 & 2.03 \\
\hline I Feel Secure Asking Others for Help & 6.74 & 4.85 & 1.89 \\
\hline My Peers View me as Knowledgeable & 6.54 & 4.80 & 1.74 \\
\hline My Peers Trust Me & 7.63 & 6.00 & 1.63 \\
\hline I am Confident in my Technical Skills & 6.77 & 5.15 & 1.62 \\
\hline My Peers View me as Competent & 6.79 & 5.25 & 1.54 \\
\hline I Feel Confident & 6.44 & 5.00 & 1.44 \\
\hline I Have an Absence of Anxiety & 6.00 & 4.59 & 1.41 \\
\hline I am Not Intimidated & 6.33 & 4.97 & 1.36 \\
\hline I Feel Adequate & 6.92 & 5.87 & 1.05 \\
\hline I Do Not Feel I Have to Represent all Women & 4.85 & 3.79 & 1.05 \\
\hline
\end{tabular}

\subsection{Favourability of Experiences between Majority Male and Majority Female Teams}

Figure 1 indicates how strongly participants agreed or disagreed with the questions respective to their experiences on male majority teams compared to their experiences on female majority teams. The greater the rating number, the more positive the experience; the lower the rating number, the more negative the experience. Without exception, participants reported all questions more favourable when experienced on majority female teams.

- "I Feel Included" - the highest score in the survey suggests women experience some form of exclusion working with male majority teams. This rating could be explained by studies showing that males use communication to establish and increase their social status while females use communication to create relationships and establish equality with their peers [10].

- "I am willing to show weakness" - the lowest score under majority male teams; was the least favourable experience of all the questions indicating an extreme aversion to showing weakness. This situation reflects an unfortunate learning environment, as it is known that learning outcomes improve when students feel comfortable showing weakness and asking for help [11].

- "I do not feel I have to represent all women" - the lowest score under majority female teams; was less than favourable in both majority conditions. Follow-up conversations with women indicate participants feel this pressure because they are in male-dominated classes and majors. The micro-climate on all-female teams may have eased specific strains, but they continued to be affected by the broader context. However, more research is required to confirm this position. 


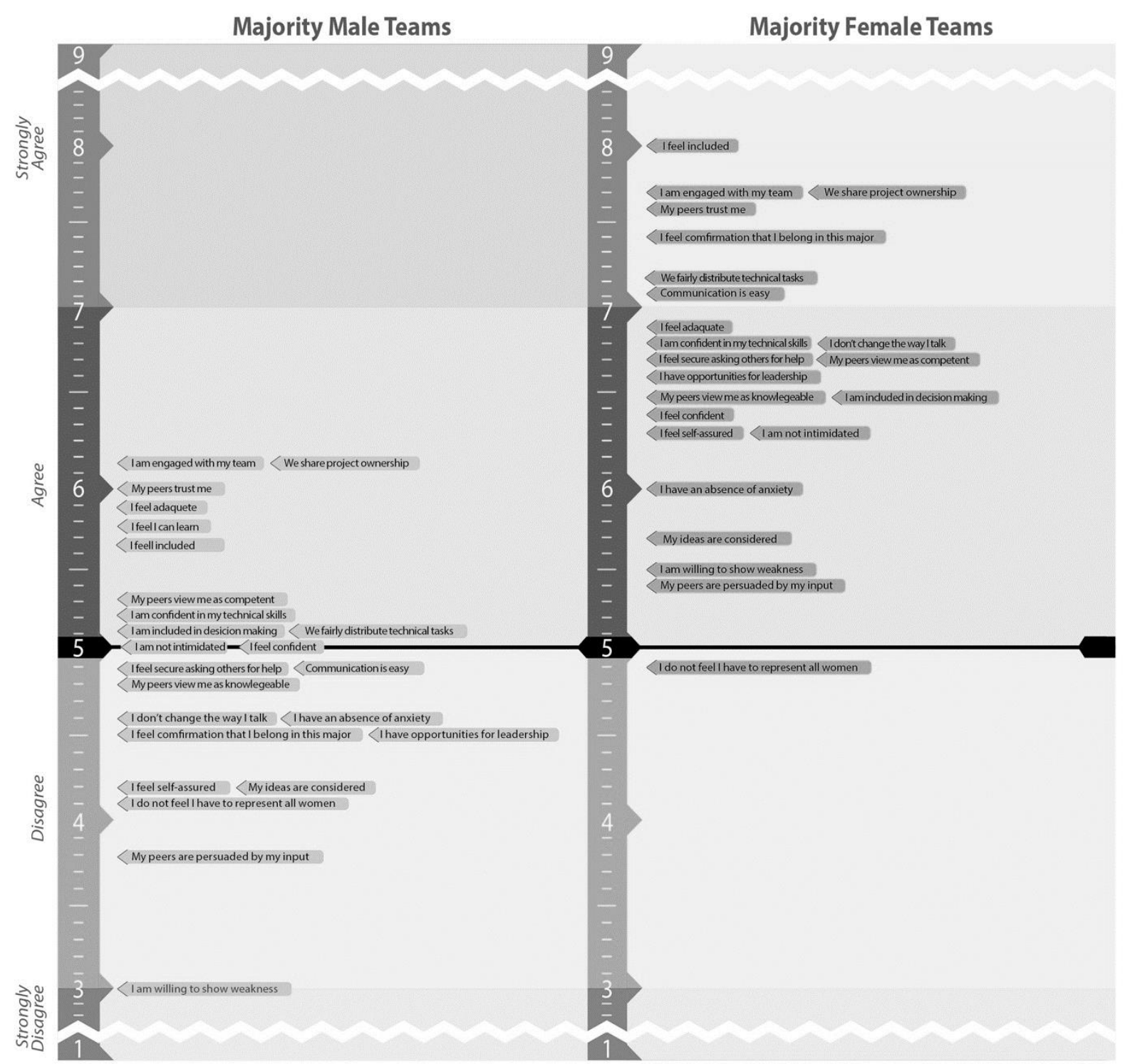

Figure 1. Favourability of experience between male and female majority teams. The greater the number, the more positive the experience and vice versa

\subsection{Questions Re-ranked by Score Difference}

The graphs on the next page re-order the questions based on the score differences between the majority male and female team ratings in the "self-perception" category, Fig. 2 and in the "in-team participation" category, Fig. 3. Notably, none of the questions performed better in the majority male teams category.

- "I feel confirmation that I belong in this major" - the highest score in self-perception deserves further exploration but suggests women experience enjoyment, responsibility, engagement, and positive learning experiences in their chosen major primarily when stereotype threat is reduced in team projects. This result could have a direct impact on the number of women disengaging from the design and engineering disciplines early in their careers $[4,5]$.

- "I have opportunities for leadership" and "we have fair distribution of technical tasks" - the highest scores in team-participation indicate that women miss out on these learning experiences while participating in majority male teams. This condition could be explained by research that shows that females tend to problem solve as a group (we all share equally in leadership and task distributions), whereas men problem solve individually (I will do this, and he will do that) [12].

\section{DISCUSSIONS}

At Brigham Young University, the entering freshman class in engineering and technology (which includes design) has consisted of $20-21 \%$ women over the last eight years. When viewing those cohort's graduation rates five years later, statistics indicate that undergraduate degrees awarded consisted of 9- 
$10 \%$ women. During their educational experience, roughly $50 \%$ of the women entering our college decide it is no longer a "fit" for them and change majors. There is no data on why they are leaving. Still, this study suggests that women's ongoing exposure to the social threat they experience on male majority teams and programs could play a role in that decision.
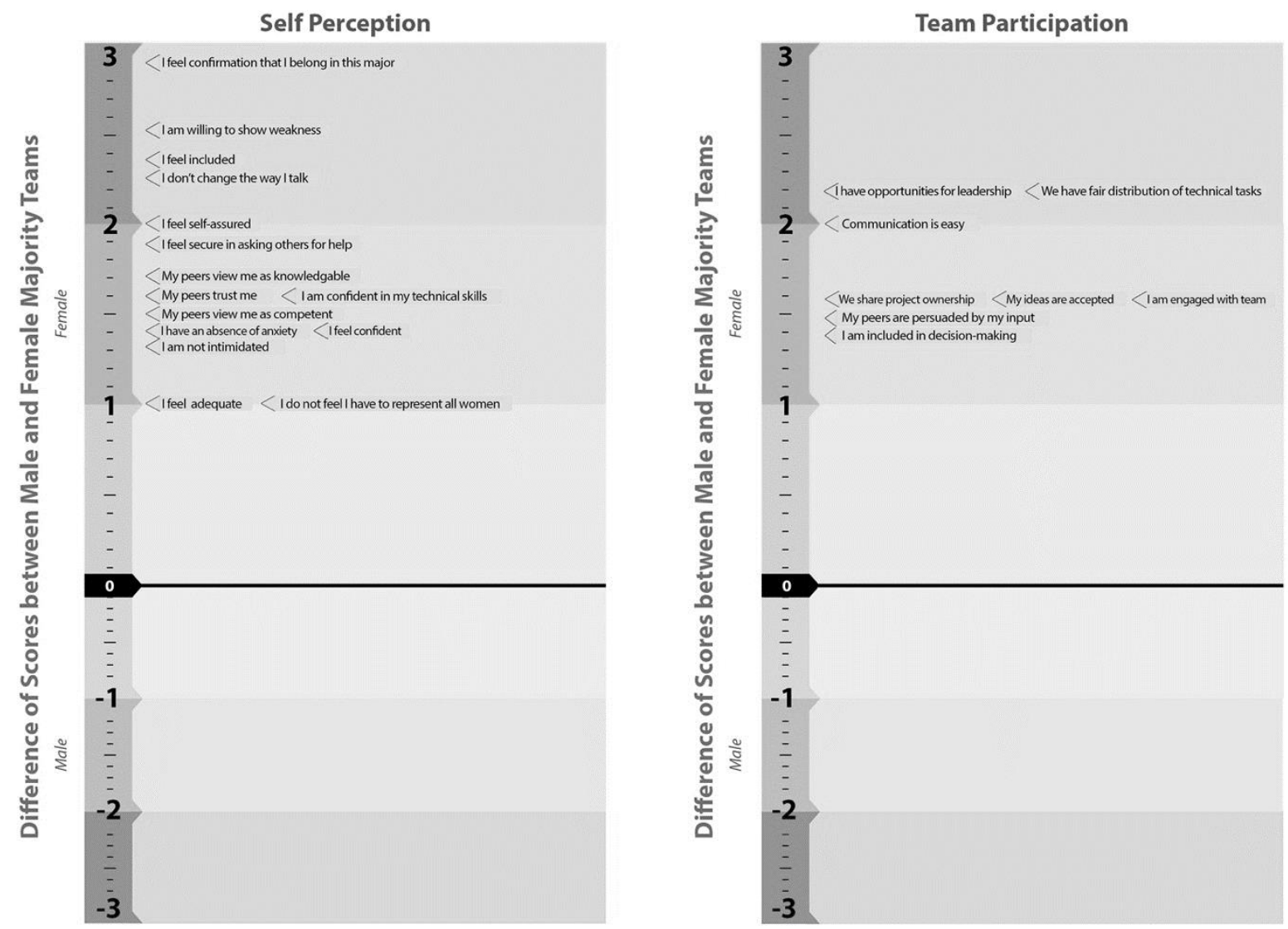

Figures 2 and 3. These graphs re-order the 23 questions by the difference in scores. The higher the rating on this graph, the greater the disparity in educational experience between participation on a majority female team (yellow) and a majority male team (blue).

The majority of design and engineering programs at universities have higher male enrolments than their female counterparts $[13,6]$. Additionally, these majors rely heavily on group work projects in their curriculum to prepare students to collaborate on teams during their careers. Casual observations and conversations on this topic indicate when there are fewer women students in a course, they are placed individually or in pairs on male majority teams. This scattering of women across the teams may appear to be the fairest and least discriminatory treatment of building teams. However, Steele found that for women to feel comfortable and involved in teams, their team should have a "critical mass" of no less than $40 \%$ female. The social threat these women experience being the sole woman on a team is neither reasonable nor appropriate and places them at a distinct educational disadvantage in those teams. This disadvantage may cause the gradual disassociation and dissatisfaction of women in engineering and design fields throughout their undergraduate experiences.

Fouad [14] found that two of the top three reasons women decide to leave engineering jobs are "unmet achievement needs that reflected a dissatisfaction with effective utilization of their math and science skills, and...unmet needs from a lack of recognition at work, and adequate opportunities for advancement". Seron [15] reports that effective strategies to improve women's "fit" in the culture of engineering are to address their experiences in college "coursework rituals and team projects".

To achieve positive educational experiences for all students in a classroom, educators should be aware of the effects and behavioural signs of stereotype threat and build teams with a critical mass reflecting the $60 \%$ - $40 \%$ gender balance male/female or female/male Steele recommends. This solution aims to increase the positive learning experiences of all students within their chosen programs, with the hope of improving women's education in the future. 
We acknowledge that the survey could be improved and distributed to more extensive and diverse female students. Even so, there is an overwhelming sense of preference towards majority female groups in team educational settings. While this study has weaknesses, we believe it is worth pursuing further and should be a vital part of conversations regarding the future of equality in design and engineering education.

\section{CONCLUSIONS}

My recent experiences running majority female team projects have been overwhelmingly positive. They are not without their unique issues, and the women initially feel some gender discrimination when the teams are organized. However, those students who initially complained the loudest also returned 4-8 weeks later and thanked me for the wonderful learning experience. I will never again isolate a woman on a team project.

To enhance learning experiences for women and enable them to hold leadership roles on a team, perform technical tasks, be heard, and feel like they fit in, a 60/40\% team gender composition should be the guideline for undergraduate group projects. It is also important to remember that stereotype threat is not limited to gender issues but can also include a student's nationality, age, religion, etc. Stereotype threat is real, and how the micro-climates educators manage, specifically how educators form teams for group projects, will affect the minority's positive or negative educational experiences.

\section{REFERENCES}

[1] Steele, C.M. Whistling Vivaldi: How Stereotypes Affect us. 2011 (W.W. Norton \& Company, New York, New York).

[2] Murphy, M.C., Steele, C.M., Gross, J.J. Signalling Threat: How Situational cues Affect Women in Math, Science, and Engineering Settings", Psychological Science, 2007, 18(10), pp. 879-885.

[3] Walters, K. Hegemony in Industrial Design: A Study of Gendered Communication Styles. In 20th International Conference on Engineering and Product Design Education, Dyson School of Engineering, Imperial College, London, September 2018.

[4] Woodcock, A., Hernandez, P.R., Estrada, M., Schultz, P.W. The Consequences of Chronic Stereotype Threat: Domain Disidentification and Abandonment. Journal of Personality and Social Psychology, 2012,103(4), pp. 635-646.

[5] Bruce, M. A missing link: women and industrial design, Design Studies, 1985, 6(3), pp. 150-156.

[6] Rincon, R. SWE Research Update: Women in Engineering By the Numbers. Available: https://alltogether.swe.org/2019/11/swe-research-update-women-in-engineering-by-the-numbersnov-2019/ [Accessed 2021, 06, 03] 2019, November.

[7] UK Engineering Council, The Accreditation of Higher Education Programmes (AHEP), August 2020, Vol. 4, pp. 11, 29-30, 34-35. Available: https://www.engc.org.uk/media/3464/ahep-fourthedition.pdf

[8] Scott, R. Strength in Diversity Act of 2020, US Committee on Education \& Labour, 2020. Available: https://edlabor.house.gov/imo/media/doc/Strength\%20in\%20Diversity\%20Act\%20$\% 20$ Fact\%20Sheet.pdf

[9] Basic Act on Education, Act No. 120 of December 22, 2006, MEXT, Japan. Available: https://www.mext.go.jp/en/policy/education/lawandplan/title01/detail01/1373798.htm

[10] Alberts, Jess K., Thomas K. Nakayama, and Judith N. Martin. Human Communication in Society, 2010 (Pearson Higher Education), pp. 113-15.

[11] Dweck, C.S., Mindset: The New Psychology of Success. 2006, (New York, Random House)

[12] Conner, M. Understanding The Differences Between Men and Women. Available: http://www.crisiscounseling.com/Relationships/DifferencesMenWomen.htm [Accessed 2021, 21 May] 2008.

[13] Fairs, M. UK design has "shocking gender imbalance" according to Design Museum research. Available: https://www.dezeen.com/2018/12/05/design-museum-research-women-design-uk/ [Assessed 2021, 06, 03] 2020, December.

[14] Fouad, N., A., Chang, W., Wan, M., and Singh, R. Women's Reasons for Leaving the Engineering Field, Frontiers in Psychology, 2017, Vol. 8, pp. 875.

[15] Seron, C., Silbey, S., S., Cech, E., Rubineau, B. Persistence Is Cultural: Professional Socialization and the Reproduction of Sex Segregation, Work and Occupations, 2015, 43(2) pp. 178-214. 